\title{
Delik içi tornalamada kesici ucun ve delik işleme barasının delik işlemeye etkisi
}

\section{Influence of insert and boring bar on boring in internal turning}

\author{
Yunus KAYIR ${ }^{1}$, Yasin ERKOÇAK ${ }^{2 *}$ \\ ${ }^{1}$ Gazi Üniversitesi, İmalat Mühendisliği Bölümü, ykayir@gazi.edu.tr \\ ORCID: https://orcid.org/0000-0001-6793-7103 \\ ${ }^{2}$ Dicle Üniversitesi, Uçak Gövde Motor Bakım Bölümü, yasin.erkocak@ dicle.edu.tr \\ ORCID: https://orcid.org/0000-0001-5808-3425
}

\begin{tabular}{l}
\hline MAKALE BİLGILERİ \\
\hline Makale Geçmişi: \\
Geliş 27 Ekim 2021 \\
Revizyon 27 Aralı 2021 \\
Kabul 27 Aralık 2021 \\
Online 31 Aralık 2021 \\
\hline
\end{tabular}

Anahtar Kelimeler:

Delik işleme barası, delik içi tornalama, kesici uç, işlenebilirlik, yüzey pürüzlülüğü, titreşim

\begin{abstract}
ÖZ
Delik içi tornalama işlemi önceden delinmiş veya döküm yoluyla elde edilmiş olan deliklerin belli ölçülere getirilmesiyle yapılan bir delik genişletme işlemidir. Delik işleme, delik toleransı dairesellik ve yüzey pürüzlülüğü açısından son derece önemli ve hassas bir işlemdir. Delik içi tornalama esnasında istenilen yüzey kalitesine kesme parametrelerinin yanı sıra kullanılan kesici ucun ve kullanılan delik işleme barasının doğrudan etkisi vardır. Bu çalışmada; delik içi tornalama işlemine yönelik yapılmış olan çalışmalar derlenmiştir. Bulunan yayınlar, kullanılan delik işleme barasının (malzemesi, boy/çap (L/D) oranı, sönümleme yöntemleri) ve kesici ucun (malzemesi, geometrisi yarıçap değeri, kaplaması) işlenen yüzeyin pürüzlülüğüne, delik geometrisine, takım aşınmasına ve kesme kuvvetlerine etkisi açısından tek tek ele alınmıştır. Yapılan incelemeler sonucunda, malzemesi çelik olan delik işleme barasının daha ekonomik olduğu, karbür delik işleme barasının daha büyük L/D oranına sahip deliklerin işlenmesinde daha iyi olduğu, kullanımı oldukça yeni olan titreşim sönümlemeli baraların ise kesme kuvveti, yüzey pürüzlülüğü ve takım aşınmasını önemli derecede azalttığı ileri sürülmüştür. Bununla birlikte, kullanılan kesici uçlarda ise, küçük uç yarıçapına ve pozitif kesme açılarına sahip olanların arzu edilen delik geometrisi ve toleransların elde edilmesinde daha uygun olduğu, serbest yüzey ve krater aşınmalarının meydana geldiği, kaplamalı uçlarla yüzey pürüzlülüğü ve aşınma üzerinde daha iyi sonuçlara ulaşıldığı ifade edilmiştir.
\end{abstract}

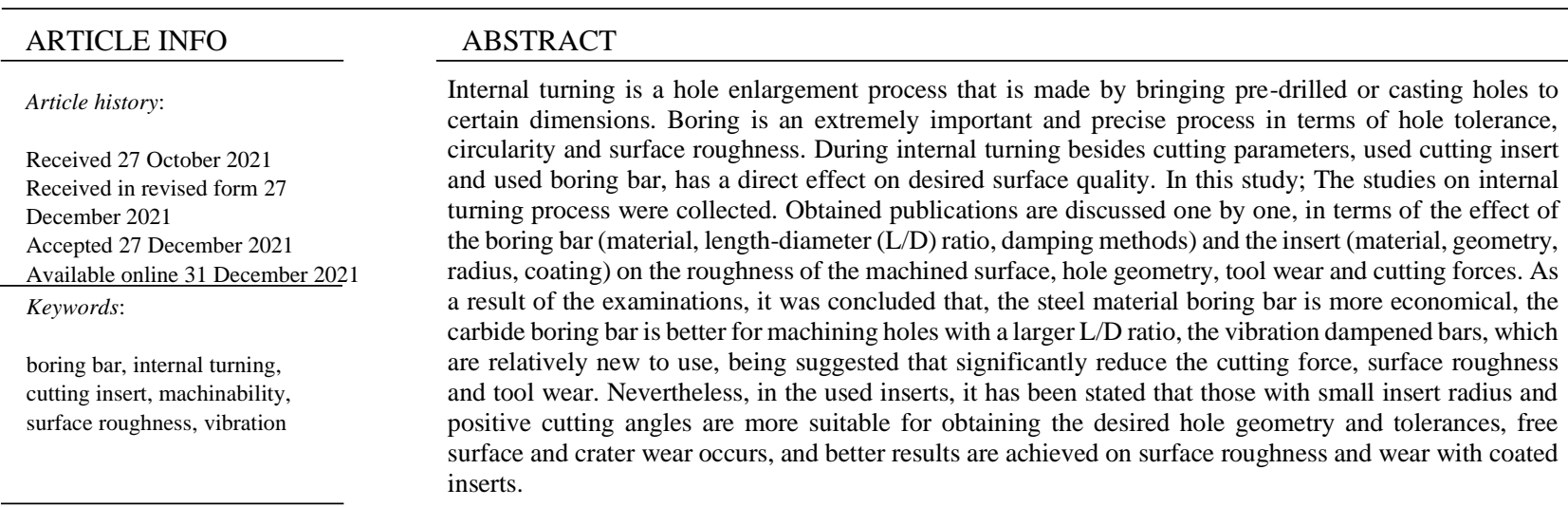

Doi:10.24012/dumf.1051439

* Sorumlu yazar

\section{Giriş}

Delik içi tornalama işlemi, önceden delinmiş veya döküm yoluyla elde edilmiş deliklerin, istenilen ölçüye getirilmesiyle yapılan bir delik genişletme işlemidir. Delik işleme barası genellikle bir ucu sabit diğer ucu ise kesme kuvvetlerine maruz kalan bir çubuktur (Şekil 1). İşleme sırasında delik işleme barası farklı yönlerde titreşimlere maruz kalır. Bu titreşimler, önemli bir kalite parametresi olan yüzey pürüzlülügüünü doğrudan etkiler. Yüzey pürüzlülüğünü kontrol etmek için delik işleme barası titreşimlerini kontrol etmek önemlidir. Titreşimler, kullanılan kesme parametrelerinin bir sonucudur [1]. Kesme parametreleri dışında delik işleme barasının boy/çap (L/D) oranı da titreşime neden olur. [2]. Daha büyük delik barası; uzunluğu nedeniyle delik işlemede, takım titreşimi, zayıf yüzey kalitesi, gürültü oluşumu, hızlı takım aşınması ve takım tezgâhının ömrünün kısalması ile sonuçlanan önemli bir faktör olarak kabul edilir [3]. Delik işleme barası ince ve uzun olduğunda, deliğin doğruluğunu ve yüzey kalitesini azaltan aşırı statik sapmalara veya kendiliğinden uyarılan tırlama titreşimine maruz kalır. Bu durum, kesici ucun daha hızlı aşınmasına neden olur [4]. Delik içi tornalamada yüzey pürüzlülüğünü, takım aşınmasını kesme kuvvetlerini titreşimleri azaltmak, istenilen geometriyi elde etmek amaciyla en uygun kesme parametreleriyle en uygun işlenebilirliğin belirlenmesine yönelik farklı delik işleme 
barası malzemeleri ve kesici uçlar kullanılarak birçok çalışmanın yapıldığg görülmüştür.

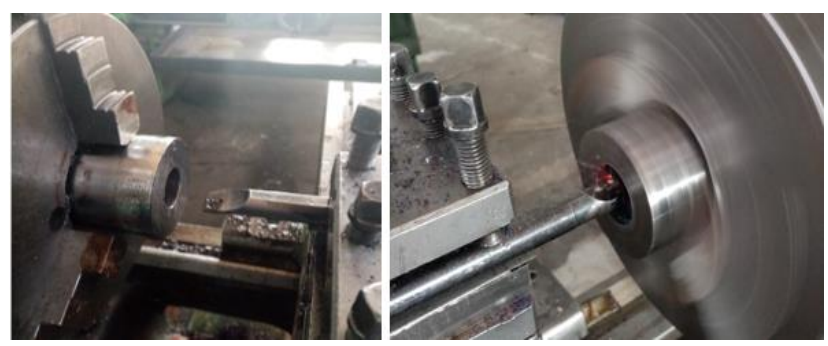

Şekil 1. Delik içi tornalama işlemi (delik barası/kateri)

Genel itibari ile yapılmış olan çalışmalarda, L/D oranının yüzey pürüzlülüğü ve dairesellik üzerinde etkili olduğu ileri sürülmüştür. Çelik baranın kullanımı, küçük delik boyları $(\mathrm{L} / \mathrm{D}<4)$ için uygun olurken, büyük delik boylarında (L/D $>4)$ karbür baranın kullanımının daha uygun olabileceği, ayrıca karbür baranın çelik baraya göre titreşimi azalttığ ifade edilmiştir [5,6]. Kesici ucun da, titreşim üzerinde etkili olduğu; [7,8], titreşim sönümlemeli (AVB: Anti Vibration Bar) delik baralarının titreşimi önemli derecede azaltarak delik içi yüzey pürüzlülüğünü iyileştirdiği, karbür baralara göre daha uzun takım ömrüne sahip olduğu, dolayısı ile de daha az maliyetli olabileceği belirtilmiştir [15]-[17]. Bununla birlikte incelenen çalışmalarda, farklı çaplara, malzemelere ve özelliklere sahip delik işleme baraları ile farklı geometrilere, uç yarıçaplarına ve malzemelerine sahip kesici uçların da kullanıldığı görülmüştür. Bu makalede, deliklerin tornalanarak işlenmesine yönelik son 20 y1la ait yapılmış olan çalışmalar bir araya toplanmıştır. Ulaşılan tüm makaleler, kullanılan delik barası, kesici uç, işlenen malzeme, kesme parametreleri, gibi faktörler, açısından tek tek ele alınmıştır. Sonuç olarak belirlenen bu faktörlerin işlenen deliklerin yüzey pürüzlülüğü, geometrisi ve toleransları açısından etkisi ortaya konmaya çalışılmıştır.

\section{Materyal ve metot}

Delik içi tornalama çalışmalarında kullanılan malzemeler, delik işleme baraları, kesici uçlar, L/D oranları (delik işleme barası bo/çap oranları) ve yöntemler başlıklar halinde değerlendirilmiştir.

\section{Kullanılan Malzemeler}

Delik içi tornalama çalışmalarında, başta çelik malzemeler olmak üzere alüminyum, dökme demir ve toz metalurjisi yöntemi ile üretilen alaşım malzeme kullanılmıştır (Tablo 1).

Tablo 1. Delik içi tornalamada kullanılan malzemeler

\begin{tabular}{|r|l|}
\hline Çelikler & AISI (316,1018,1026, 1030, 1040, \\
& $1041,1050,4340,5200)$ EN32,C45 \\
\hline Sert malzemeler & AISI 4340, AISI52100 \\
\hline Alüminyum & AA5754, A17075 \\
\hline Dökme demir & ---- \\
\hline Alaşım & M657BA12T \\
\hline
\end{tabular}

Badadhe ve arkadaşları AISI 1041 malzemeyi 16-20-25 mm çaplarında çelik delik işleme baraları ile $1.2 \mathrm{~mm}$ uç yarıçapına sahip karbür kesici uçlarla delik içi tornalayarak yüzey pürüzlülüğünü incelemişlerdir. Araştırmacılar yüzey pürüzlülüğü üzerinde en etkili parametrenin L/D oranı olduğunu belirtmişlerdir [1]. Suyama ve arkadaşları 53.6 HRC sertliğindeki AISI 4340 çeliğini delik içi tornalamada $20 \mathrm{~mm}$ çapında çelik ve karbür delik işleme baraları ve 0.8 mm yarıçapında CBN kesici uçlar kullanarak, takım aşınması yüzey pürüzlülüğü ve titreşimi incelemişlerdir. Kesme işleminin kararlı olduğu durumlarda (küçük L/D oranlarında) yüzey pürüzlülüğünün kesici ucun geometrisinden ve kesme parametrelerinden etkilendiğini, L/D oranın büyük olduğu durumlarda ise çelik baranın talaş kaldırmada kararsız hale geldiğini, karbür baranın daha büyük L/D oranı ile kullanılabileceğini ileri sürmüşlerdir [5].

\section{Kullanılan Delik İşleme Baraları}

İncelenen delik işleme çalışmalarında yaygın olarak çelik ve karbür baralar (Şekil 2.a, 2.b) kullanılmıştır. Özellikle son yıllara ait yayınlarda ise özel tasarlanmış çeşitli titreşim sönümlemeli (AVB) baraların da (Şekil 2.c) kullanıldığı görülmektedir. Yapılmış olan deneysel çalışmalarda, işlenecek deliğin çapına ve boyuna göre, farklı boy ve çaplarda üretilmiş olan özel baraların da kullanıldığı görülmektedir (Tablo 2).

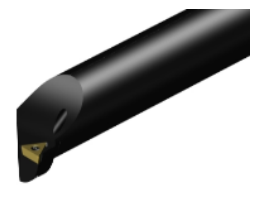

a) Çelik Gövdeli Delik Barası

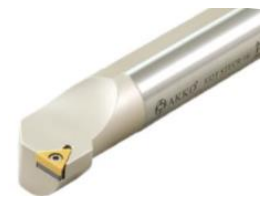

b) Karbür Gövdeli Delik Barası

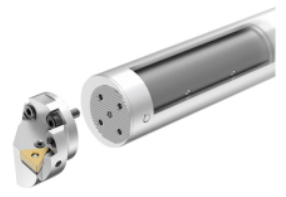

c) Titreşim Sönümlemeli (AVB) Delik Baras1
Şekil 2. Delik İçi Tornalamada Kullanılan Takım Tutucular

Tablo 2. Delik içi Tornalamada Kullanılan Delik İşleme Barası Malzemeleri ve Çapları

\begin{tabular}{|l|l|}
\hline \multicolumn{1}{|c|}{ Delik İşleme Barası Malzemesi } & \multicolumn{1}{|c|}{ Takım Tutucu Çapı (mm) } \\
\hline Çelik delik işleme barası & $10-12-16-18-25$ \\
\hline Karbür delik işleme barası & $10-20-25$ \\
\hline $\begin{array}{l}\text { Titreşim Sönümlemeli delik } \\
\text { işleme barası (AVB) }\end{array}$ & $25-32$ \\
\hline
\end{tabular}

Farklı malzemeler kullanılarak farklı özelliklerle imal edilmiş delik baralarının delik işleme üzerindeki etkilerinin de farklı olduğu anlaşılmaktadır. Örneğin, yapılan bir çalışmada, $25 \mathrm{~mm}$ çapında çelik, karbür ve titreşim sönümlemeli delik işleme baraları ile AISI 1040 malzeme işlenerek delik içi tornalamada kesme parametrelerinin dairesellikten sapmaya etkisi araştırılmıştır. Çalışmanın sonucunda, ilerleme hızının, \%23.92, kesme derinliğinin $\% 21.21$ ve bara bağlama boyunun ise \% 21.15 oranlarında dairesellikten sapmaya etkisi olduğu ifade edilmiştir [6].

\section{Kullanılan Kesici Uçlar}

İncelenen çalışmalarda yapılan delik içi tornalama deneylerinde genellikle kesici uç olarak; farklı geometrilere (üçgen, kare, vb), farklı açılara (pozitif-negatif) ve farklı uç yarıçaplarına sahip, kaplamalı/kaplamasız kesici uçlar (insert) kullanılmıştır (Tablo 3). Örneğin, bir delik içi tornalamada AISI 1018 malzeme üzerinde VBGT kodlu TiAl kaplı $0.2 \mathrm{~mm}$ ve $0.4 \mathrm{~mm}$ uç yarıçap değerlerine sahip 
karbür uçlar kullanılmış, yüzey pürüzlülüğüne etki eden kesme parametreleri belirlenmeye çalışılmıştır. Küçük uç yarıçaplı kesici uç ve yüksek pozitif kesme açısı, minimum yüzey pürüzlülüğü vermiştir [7]. Diğer bir çalışmada ise, SCMT kodlu ve 0.4 ve $0.8 \mathrm{~mm}$ uç yarıçaplara sahip kaplamalı karbür kesici uçlarla ıslak ve kuru şartlarda delik içi tornama deneyleri yapılarak elde edilen yüzey pürüzlülüğü incelenmiştir. Düşük ilerleme hızı ile büyük uç yarıçaplı kesici uç kullanıldığında, sslak işlemede yüzey pürüzlülüğünde \%80'e varan iyileşmeler elde edilmiştir [8].

Tablo 3. Delik içi Tornalamada Kullanılan Kesici Uçların Özellikleri

\begin{tabular}{|c|c|c|c|c|c|}
\hline Geometri & Kod & $A c ̧ ı$ & Uç Yarıçapı & Kaplama & Malzeme \\
\hline & TNMG & Negatif & 0.8 & --- & --- \\
\hline & TCMT & Pozitif & 0.4 & --- & Karbür \\
\hline & CCGW & Pozitif & 0.8 & $\mathrm{TiCN}+\mathrm{Al}_{2} \mathrm{O}_{3}$ & CBN \\
\hline & CNMG & Negatif & 0.8 & $\mathrm{Al}_{2} \mathrm{O}_{3}+\mathrm{ZrO}_{2}$ & Karbür \\
\hline & CCMT & Pozitif & $0.2-0.4-0.8$ & TiN & Karbür \\
\hline & DCGW & Pozitif & 0.4 & $\mathrm{TiN}$ & CBN \\
\hline & DCGT & Pozitif & $0.2-0.40 .6-0.8$ & --- & Karbür \\
\hline & DCMT & Pozitif & $0.2-0.40 .6-0.8$ & --- & Karbür \\
\hline & DNMG & Negatif & $0.4-0.8$ & Kaplamalı & Karbür \\
\hline & VBGT & Pozitif & $0.2-0.4$ & TiAlN & Karbür \\
\hline & SCMT & Pozitif & $0.4-0.8$ & $\mathrm{TiN}, \mathrm{Al}_{2} \mathrm{O}_{3}$ & Karbür \\
\hline & W & ----- & 0.4 & ----- & ---- \\
\hline
\end{tabular}

\section{Kullanılan Kesme Parametreleri}

Delik içi tornalama çalışmalarında kesme parametreleri olarak; kesme hızı (V: m/dak) veya devir sayısı (S: dev/dak), ilerleme (f: $\mathrm{mm} / \mathrm{dev})$, kesme derinliği (Ap: mm), delik barası boy/çap (L/D) oranı veya bağlama boyu $(\mathrm{mm})$, titreşim sönümleme malzemeleri (çelik, bakır, kurşun, vb) gibi birçok parametrenin kullanıldığı görülmektedir (Tablo 4).

Tablo 4. Kesme parametreleri değer aralıkları

\begin{tabular}{|c|c|c|c|}
\hline $\begin{array}{c}\text { Kesme Hızı, } \\
\text { V (m/dak) }\end{array}$ & $\begin{array}{c}\text { İlerleme, } \\
\mathbf{f}(\mathbf{m m})\end{array}$ & $\begin{array}{c}\text { Kesme derinliği, } \\
\mathbf{A p}(\mathbf{m m})\end{array}$ & $\begin{array}{c}\text { L/D } \\
\text { oranı }\end{array}$ \\
\hline $50-360$ & $0.01-0.75$ & $0.25-2$ & $3-9$ \\
\hline
\end{tabular}

Bir çalışmada, $25 \mathrm{~mm}$ çapında çelik malzemeden imal edilmiş bir delik barası ve $0.4 \mathrm{~mm}$ uç yarıçapında TiN kaplı DCMT kodlu CBN kesici uç kullanılarak AISI52100 malzemesi işlenmiştir. Yapılan delik içi tornalama sonrası elde edilen delik için çap hatası, dairesellik ve yüzey pürüzlülüğü incelenmiştir. Çalışmada $\% 62.84$ ile yüzey pürüzlülüğü açısından en önemli faktörün ilerleme olduğu saptanmıştır [9].

\section{Kullanılan Optimizasyon Yöntemleri}

Genelde, incelenen delik içi tornalama çalışmalarında elde edilen deney sonuçlarının değerlendirilmesinde Taguchi, Varyans Analizi (ANOVA), Gri İlişkisel Analiz (GRA), yapay sinir ağları (YSA), yüzey cevap metodu (RSM) gibi optimizasyon yöntemleri kullanılmıştır.

\section{Taguchi Yöntemi}

Bilindiği gibi, Taguchi metodu, dikkate alınmayan kontrol edilemeyen faktörlerin neden olduğu varyasyonları kontrol etmeyi sağlar. Taguchi, bu faktörlere karşı kontrol faktörlerinin seviyelerinin performansını ölçmek için objektif değerleri sinyal-gürültü $(\mathrm{S} / \mathrm{N})$ oranına dönüştürür. $\mathrm{S} / \mathrm{N}$ oranı, istenmeyen rastgele gürültü değeri için istenen sinyal oranı olarak tanımlanır ve deney verilerinin kalite özelliklerini gösterir. S/N oranı olarak tanımlanan üç farklı işlev vardır: Daha büyük-Daha iyi (Larger is better), Daha küçük-Daha iyi (Smaller is better), Nominal-Daha iyi (Nominal is better). Taguchi metodunun kullanıldığ1 bir çalışmada, AA5754 alüminyum alaşımının ıslak şartlarda delik büyültme işleminde, kesme parametrelerinin (V,f ve Ap), yüzey kalitesi etkisi incelenmiştir. Deneyler Taguchi L9 ortagonal tasarım düzenine göre gerçekleştirilmiştir (Tablo 5). Çok yanıtlı Taguchi yaklaşımı kullanılarak, minimum yüzey pürüzlülük değerlerinin $120 \mathrm{~m} /$ dak kesme hızı, 0.10 $\mathrm{mm} / \mathrm{dev}$ ilerleme ve $0.75 \mathrm{~mm}$ kesme derinliği koşullarında gerçekleştiği sonucuna ulaşılmıştır [10].

Tablo 5. Taguchi L9 deney tasarımı [10]

\begin{tabular}{|c|l|l|l|l|l|l|}
\hline DeneyNo & A & $\mathbf{B}$ & $\mathbf{C}$ & $\mathbf{R a}$ & $\mathbf{R z}$ & $\mathbf{R q}$ \\
\hline $\mathbf{1}$ & 1 & 1 & 1 & 2.30 & 9.73 & 2.74 \\
\hline $\mathbf{2}$ & 1 & 2 & 2 & 3.42 & 16.47 & 4.46 \\
\hline $\mathbf{3}$ & 1 & 3 & 3 & 4.31 & 17.84 & 5.47 \\
\hline $\mathbf{4}$ & 2 & 1 & 2 & 1.43 & 5.96 & 1.67 \\
\hline $\mathbf{5}$ & 2 & 2 & 3 & 2.78 & 13.09 & 3.50 \\
\hline $\mathbf{6}$ & 2 & 3 & 1 & 3.01 & 11.70 & 3.98 \\
\hline $\mathbf{7}$ & 3 & 1 & 3 & 1.61 & 5.22 & 1.30 \\
\hline $\mathbf{8}$ & 3 & 2 & 1 & 2.50 & 11.08 & 3.01 \\
\hline $\mathbf{9}$ & 3 & 3 & 2 & 3.20 & 13.75 & 4.10 \\
\hline
\end{tabular}

\section{Varyans Analizi (ANOVA)}

ANOVA, elde edilen veriler ile kullanılan parametreler arasındaki ilişkiyi belirlemeyi sağlayan bir istatiksel yöntemdir. Yapılan deneysel çalışmalarda araştırmacılar, deney parametrelerin elde edilen deney sonuçları üzerindeki $\%$ etki oranlarını belirlemek için, varyans analizi (ANOVA) yöntemini tercih etmişlerdir. ANOVA kullanılarak yapılan bir çalışmada, AISI 1040 malzemesi $0.4 \mathrm{~mm}$ ve $0.8 \mathrm{~mm}$ uç yarıçaplarına sahip kesici uçlarla delik içi tornalanmış, yüzey pürüzlülüğü, titreşim ve kaldırılan talaş hacmi değerlendirilmiştir. Kesici uç yarıçapının \%45.81 oranla titreşimi etkileyen en önemli parametre olduğu, ilerleme hızının ise yüzey pürüzlülüğü üzerinde $\% 55.57$ oranla ve kaldırılan talaş hacmi üzerinde ise $\% 51.26$ oranla en önemli kesme parametresi olduğu tespit edilmiştir [11].

\section{Gri İlişkisel Analiz Yöntemi (GRA, Grey Relational Analysis)}

Bilindiği gibi Gri ilişki Analizi (GRA) elde edilmiş olan verilerin içinden en uygun olanın belirlenmesine yönelik kullanılan bir istatiksel metottur. Bu yöntemde, elde edilen veriler (dizi) ile kullanılan parametreler arasındaki ilişki belirlenmeye çalışılır. Bunun için de ilk olarak deneysel veriler normalleştirilir. Gri ilişkisel analizde "büyük daha iyidir", "küçük daha iyidir" ve "nominal daha iyidir" 
modelleri kullanılarak optimum sonuç elde edilir. GRA yönteminin kullanıldığı bir çalışmada, bakır sönümleyicili bir delik barası ile delik içi tornalama deneyleri yapılmıştır., Taguchi yöntemine göre deneylerin yapıldığı çalışmada; GRA yöntemi kullanarak ölçülen kesme kuvvetleri ve takım aşınması için optimizasyon gerçekleştirilmiştir. Daha Küçük Daha İyidir (Smaller is better) modeline göre yapılan analizde, en iyi kesme kuvveti $342.47 \mathrm{~N}$ olarak ve en iyi takım aşınması da $0.24 \mathrm{~mm}$ olarak elde edilmiştir [12].

\section{Yapay Sinir Ağı (YSA) Yöntemi}

YSA, insan beyninin sinir ağlarını taklit ederek geliştirilen bir bilgisayar yazılımıdır. YSA yönteminde, eldeki mevcut verileri (kullanılan parametreler ile elde edilen sonuçlar) kullanarak öğrenen bir sistemin yeni verileri tahmin etmesi sağlanmaktadır. İncelenen delik işleme çalışmalarında elde edilen deney sonuçları için YSA yönteminin de kullanıldığ görülmüştür. Yapılan bir çalışmada, AISI 316 çeliği delik içi tornalanarak takım aşınması, yüzey pürüzlülüğü ve titreşim incelenmiştir. Deneylerde, DNMG $0.4 \mathrm{~mm}$ ve $0.8 \mathrm{~mm}$ uç yarıçapında karbür kesici uçlar kullanılmıştır. Belirlenen YSA modelinin, eğitimi için elde edilen deney sonuçlarından 54 tanesi kullanılmış, 15 tanesi doğrulanması için kullanılmış ve 8 adet deney ile de test edilmiştir. YSA'nın, takım titreşimini, takım aşınmasını yüzey pürüzlülüğünü azaltmak için uygun kesme parametrelerinin seçiminde yardımcı olabildiği belirtilmiştir [13].

\section{Yüzey Yanıt Yöntemi (RSM-Response Surface Methodology)}

Elde edilmiş olan verilerin değerlendirilmesinde kullanılan bir yöntemdir (Yüzey yanıt yöntemi olarak bilinir). RSM yönteminde, istatistiksel ve matematiksel teknikler birlikte kullanılır. RSM, bir optimizasyon (en iyi duruma getirme) tekniğidir. İncelenen delik işleme çalışmalarında, deneysel verilerin değerlendirilmesinde RSM yönteminin de tercih edildiği görülmüştür. Örneğin, deneysel bir çalışmada, RSM ile titreşim ve yüzey pürüzlülüğü değerlendirilmiştir. Yapılan çalışmada, $16 \mathrm{~mm}$ çapında çelik bara ile $0.8 \mathrm{~mm}$ uç yarıçapında CCMT kodlu karbür uçlar kullanılmıştır. Deneylerden elde edilen yüzey pürüzlülüğü ve titreşimler incelenmiştir. RSM yöntemi ile tahmin edilen optimum (en uygun) titreşim ve yüzey pürüzlülüğü için doğrulama deneyleri yapılmış ve yüzdelik hata oranları hesaplanmıştır. Yüzey pürüzlülüğü ve titreşim için yüzde hata aralığ sırasıly \%-3 ila \%3 ve \%-6 ila \%7 olduğu belirlenmiştir [14].

\section{Araştırma ve bulgular}

Delik içi tornalama ile ilgili yapılan çalışmalar incelendiğinde, titreşim, yüzey pürüzlülüğü, kesme kuvvetleri, takım aşınması, dairesellik, delik barasının boy çap oranı (L/D oranı) gibi kriterlerin önemli faktörler olduğu görülmüştür.

\section{Titreşim ve Boyutsal Doğruluk (Çaptan sapma, Dairesellik)}

Delik içi tornalama işlemlerinde, kullanılan delik barasının çap1 küçük ve boyu uzun olduğunda, delik geometrisinin bozulduğunu yüzey kalitesinin kötüleştiğini ve titreşime (tırlama) maruz kalınacağını yapılan çalışmalar göstermektedir (Şekil 3). Dolayısı ile işlenen delik için arzu edilen kalitenin (geometri, tolerans, pürüzlülük, vb) elde edilebilmesi için titreşimin azaltılması (sönümlme) gerekmektedir. Genel olarak, titreşim sönümleme yöntemleri aktif ve pasif sönümleme olarak iki kategoriye ayrılmıştır. Aktif sönümleme için, işlenebilirlik sırasında gerçek zamanlı işlem verileri elde edilir ve piezoelektrik aktüatörlerle (eyleyici) sinyallerin üretilmesi için analizler yapılır. Pasif sönümleme için ise, titreşim emiciler, titreşim damperleri, ayarlı damperler ve parçacık sönümleme işlemleri kullanılabilir. Bunun yanında, delik içi tornalama yapılırken titreşimi (tırlamayı) azaltmak ve boyutsal doğruluğu (dairesellik) sağlamak için kullanılan kesme parametrelerinin de optimizasyonunun önemli olduğu görülmüştür.

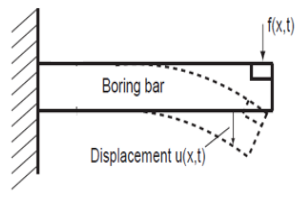

$\mathbf{a}$

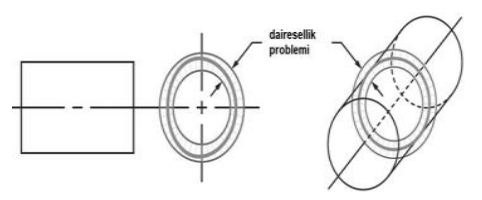

b

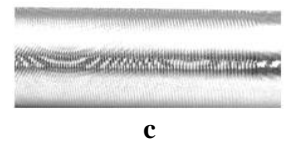

Şekil 3. a) Delik kateri deplasmanı b) Dairesellik problemi c) Titreşimli iş parçası yüzeyi

$25 \mathrm{~mm}$ çapında nanokompozit kaplamalı ve kaplamasız çelik bara kullanılarak $(\mathrm{L} / \mathrm{D}=5)$ yapılan bir çalışmada, mekaniksel titreşimler incelenmiştir. Kaplanmış bara, işleme sırasında ölçülen mutlak ses seviyesini yaklaşık \% 90 oranında azaltmış, yüzey pürüzlülügüünü yaklaşık 3-6 $\mu \mathrm{m}$ 'dan $2 \mu \mathrm{m}$ 'a kadar düşürmüş̧ür. [15]. Farklı viskoelastik sönümleme malzemelerinin (PTFE, PVC, Butyl Rubber) kullanıldığı delik barası ile yapılan bir başka çalışmada ise, sönümleme malzemesinin yüzey pürüzlülüğü üzerinde etkileri araştırmıştır. $20 \mathrm{~mm}$ çapında çelik bara ile yapılan deneylerde yüzey pürüzlülüğünün PTFE malzeme ile yaklaşık \%25-30 oranında azaldığı belirtilmiştir [16]. $20 \mathrm{~mm}$ çapında çelik, karbür ve sönümlemeli bara kullanılarak yapılan diğer bir çalışmada ise, karbür baranın çelik baranın yetersiz kaldığı durumlarda kullanılabileceği önerilmiştir. Parçacık sönümleyicilerin çelik baraların, titreşimini azalttığı ve daha büyük L/D oranlarında kullanılmasını sağladığı görülmüştür. Dolayısı ile bu durum, sönümlü çelik baraların, karbür baralara göre basit ve ucuz bir alternatif olabileceğini göstermiştir. [17]. Delik baralarının sönümlendirildiği bir çalışmada, $25 \mathrm{~mm}$ çapında çelik bara $8 \mathrm{~mm}$ çapında delinerek içerisine farklı boyutlarda sönümleme parçacıkları $(\mathrm{FeC}, \mathrm{Cu}, \mathrm{Pb}, \mathrm{CuZn}, \mathrm{Ag}, \mathrm{Cr}$ ) yerleştirilmiş ve delik içi tornalamada parçacık boyutu, yoğunluk ve sertliğin yüzey pürüzlülüğü üzerindeki etkisi araştırılmıştır (Şekil 4). Parçacık boyutu ne kadar küçük olursa, sönümün o kadar yüksek olacağı, daha yüksek 
yoğunluğa sahip malzemeler tercih edilmesi gerektiği, sert parçacıkların iyi bir sönümleme sağladığı ve yüzey kalitesini iyileştirdiği belirtilmiştir. Çelik bilyeler, diğer parçacıklara kıyasla daha iyi yüzey kalitesi vermiştir [18].
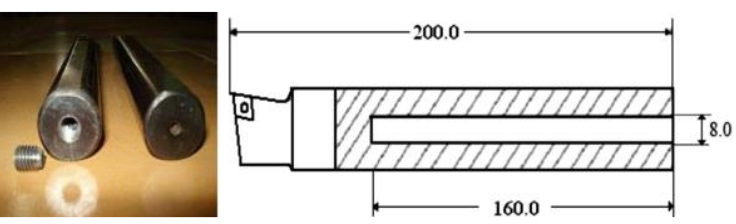

(a)
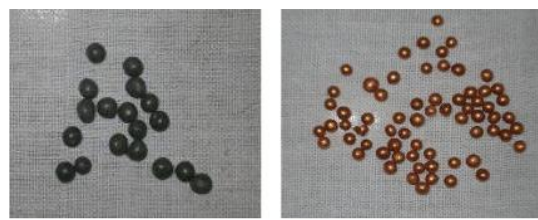

(b)

Şekil 4. a) Titreşim Sönümlemeli delik işleme barası b) Kurşun ve bakır partiküller [18]

Bir çalışmada ise, $20 \mathrm{~mm}$ çapında çelik bara üzerine sönümleme için yapıştırılan karbon fiber malzemesinin titreşimi azalttı̆̆ belirtilmiştir. Sönümleme kullanılmayan normal bir baranın frekansı, kesme hızı, ilerleme, kesme derinliği ve takım uzunluğu arttıkça artmış ve frekans $2225.32 \mathrm{~Hz}$ olarak elde edilmiştir. Karbon fiber malzeme ile sönümlendirilmiş bir baranın oluşturduğu frekans ise 1586.21 Hz'e düşmüştür [4]. $16 \mathrm{~mm}$ çapında çelik bara üzerinde çeşitli sönümleme malzemeleri (PU, PVC, Teflon) kullanılarak yapılan çalışmada, Teflon sönümleme ile yüzey pürüzlülük değerinin \% 33'e kadar, frekans değerinin \% 13'e kadar düştüğü tespit edilmiştir [19]. $20 \mathrm{~mm}$ çapında çelik bara ve $0.8 \mathrm{~mm}$ yarıçapında kaplamalı CBN kesici uç ile AISI 4340 çeliğini delik içi tornalayarak, hava destekli ve hava desteksiz çelik ve kurşun partiküllerin yüzey pürüzlülüğü üzerindeki etkilerinin incelendiği diğer bir çalışmada, kesme parametreleri, partikül sıkıştırma oranı, partikül malzemesi, partikül boyutu değerlendirilmiştir. Çalışmada, delik barası, 70 ve $120 \mathrm{~mm}$ boyutlarda kullanılmıştır. Hava akışlı partikül sönümleyici, $120 \mathrm{~mm}$ boydaki bara için, yüzey pürüzlülüğünü yaklaşık \%60 oranında azaltmıştır. Hava akışının, delik barasının kullanılan boyuna bağlı olduğu, kurşunla doldurulmuş baranın yüzey pürüzlülüğünü azaltmada daha etkili olduğu ifade edilmiştir [20]. Yapılan bir delik işlemede tırlamayı (kesici ucun yer değiştirmesi) bastırmak için $12 \mathrm{~mm}$ çapındaki bir çelik bara, bakır ve kurşun parçacıklarla sönümlenmiş ve alüminyum malzemelerin delik içi tornalanmasında kullanılmıştır (Şekil 5). Çalışmanın sonucunda, sönümlemeli baranın tırlamaya karşı direncinin, normal baradan daha büyük olduğu, titreşimi yaklaşık \% 61 oranında azalttığı ve yüzey kalitesini de \% 88 oranında iyileştirdiği belirlenmiştir [21].

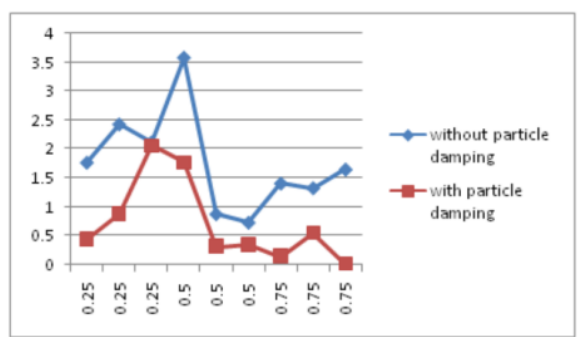

(a) titreşim - kesme derinliği grafiğgi

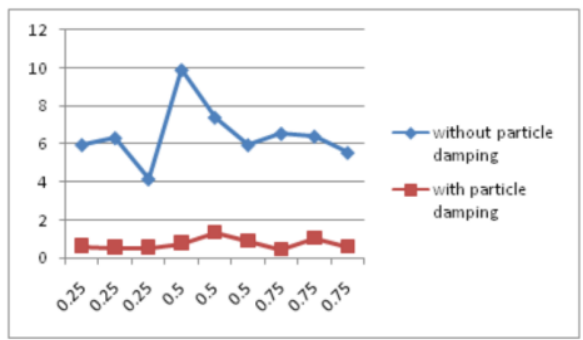

(b) yüzey pürüzlülüğü - kesme derinliği grafiği

Şekil 5. Sönümlemeli (with particle damping) ve sönümlemesiz (without particle damping) delik işleme baralarıyla elde edilen titreşim ve yüzey pürüzlülüğü grafikleri [21]

Delik barası ile yapılan bazı çalışmalarda, delik içi konikliğinin (delik başlangıç çapı ile delik çıkış çapı arasındaki ölçü farkı), ortaya çıkabileceğinden bahsedilmiştir. Delik içi konikliğin giderilmesinde ise, ilerleme değerlerinin artırılmasının yanı sıra L/D oranının düşürülmesinin etkili olduğu, kendinden sönümleme özelliğine sahip karbür baraların, delik işleme için en iyi seçim olacağı belirtilmiştir [22].

\section{Takım aşınması ve takım ömrü}

Delik içi tornalamada takım aşınması ve takım ömrü ile ilgili çeşitli çalışmalar mevcuttur. Titreşim sönümlemeli (tool with copper damper - bakır sönümleyicili takım ) ve titreşim sönümlemesiz (tool without damper- sönümleyicisiz takım) delik baralarının takım sıcaklığı ve takım aşınması üzerindeki etkilerinin deneysel olarak değerlendirildiği bir çalışmada (Şekil 6), (number of trails: deney numarası, tool temperature: takım sıcaklığı) titreşim sönümleyicilerin, delik barasının kararlılığını arttırdığı belirtilmiştir. Delik barasının sönümleme kabiliyeti ve sertliği arttığında takım aşınmasının azaldığı, takım ömrünün uzadığı belirtilmiştir. Sönümlemeli bara sıcaklığı $(117.6 \mathrm{~F})$, normal bara sicaklığına (170.2 F) göre daha düşüktür. Sönümlemeli bara ile daha az ses ve daha uzun takım ömrü elde edilmiştir [23].

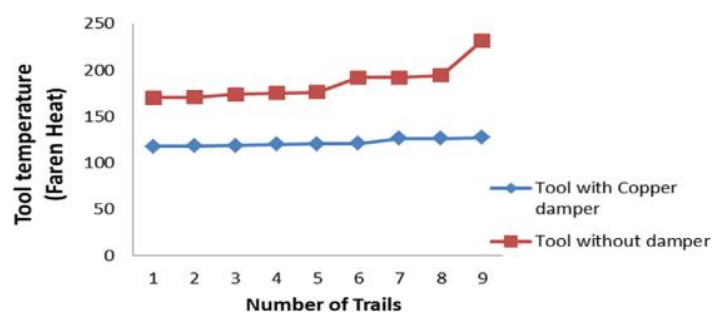

Şekil 6. Sönümlü ve sönümsüz delik işleme baralarının deney numarası kesici uç sıcaklığı grafiği [23] 
Bir çalışmada, $20 \mathrm{~mm}$ çapında çelik ve karbür bara ve CCGW geometriye sahip $0.8 \mathrm{~mm}$ yarıçapında CBN kesici uçlarla delik içi tornalamada titreşim ve takım aşınması incelenmiştir. Delik barası malzemesi takım ömrünü etkilemiştir. Titreşim yüksek olduğunda, difüzyon etkili aşınma mekanizması iken titreşim en düşük seviyedeyken etkili aşınma mekanizmasının abrasiv aşınma olduğu görülmüştür. Karbür baranın çelik baraya göre daha uzun ömürlü olduğu, çelik baranın maruz kaldığı titreşimin karbür baraya göre biraz daha yüksek olduğu ve bunun da takım ömrü üzerinde küçük bir etkiye neden olduğu belirtilmiştir [24]. $32 \mathrm{~mm}$ çapında çelik bara ve $0.8 \mathrm{~mm}$ yarıçapa sahip DCMT kaplamasız karbür uçlarla yapılan bir çalışmada, EN32 sertleştirilmiş çelik malzeme delik içi tornalanarak takım aşınması ve yüzey pürüzlülüğü incelenmiştir. Kaplamasız karbür kesici uçlarda serbest yüzey aşınması meydana gelmiştir. Çelik bara için kullanılan parçacık sönümlemenin $(\mathrm{Bbh}=$ çelik bilyelerle dolu içi boş delik işleme barası, Bbs=normal sönümsüz bara), takım gürültüsünü önemli ölçüde azalttığ1, yüzey pürüzlülüğünü iyileştirmede ve takım aşınmasını azaltmada iyi bir etkiye sahip olduğu belirtilmiştir (Şekil 7) [25].

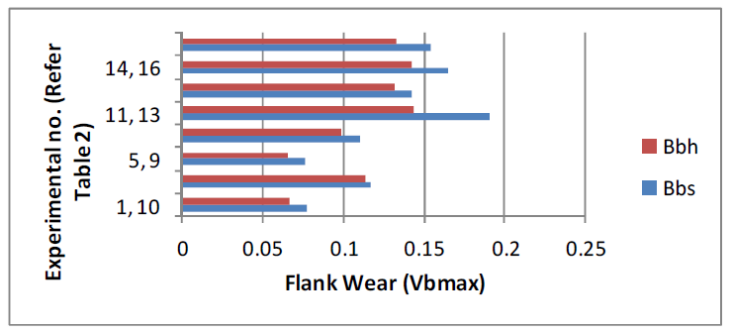

Şekil 7. Deney numarası serbest yüzey aşınması grafiği [25]

Toz metalurjisi ile elde edilen $\mathrm{Fe}-\mathrm{C}-\mathrm{Cu}-\mathrm{Ni}-\mathrm{Mo}$ alaşıml malzemenin, PCBN kesici uçlarla işlenerek yüzey pürüzlülüğünün incelendiği bir çalışmada, kesme hızının takım aşınmasında en büyük etkiye sahip olduğu belirtilmiştir. Kesme hızı artıkça aşınma tiplerinin, serbest yüzey aşınması ve krater aşınması olarak ortaya çıktığı, düşük kesme hızında aşındırıcı ve orta kesme hızında da difüzyon gibi aşınma mekanizmalarının görüldüğü ifade edilmiştir. Aşınmanın artmasıyla da, yüzey pürüzlülüğünün $\operatorname{arttı̆̆}$ vurgulanmıştır [26].

\section{Kesme kuvvetleri}

Delik içi tornalamada, delik barası, kesici uç ve kesme parametreleri seçimine göre kesme kuvvetleri farklılık göstermektedir. Bununla birlikte, delik baralarında kullanılan sönümleyicilerin de kesme kuvvetleri üzerinde etkili olduğu yapılan çalışmalarda görülmüştür. Örneğin yapılan bir çalışmada, çelik bara üzerine monte edilen sönümleyicinin (with impact damper) titreşimi bastırarak delik barasına doğal bir sönümleme yeteneği kazandırdığı, elde edilen deneysel sonuçlardan, titreşim sönümlemeli delik barasının kesme kuvvetlerini etkili bir şekilde azalttığı (Cutting force - variable feed test, kesme kuvvetleri - farklı ilerleme deneylerinde, Cutting force - variable speed test, kesme kuvvetleri - farklı kesme hizı deneylerinde) görülmüştür (Şekil 8) [3].

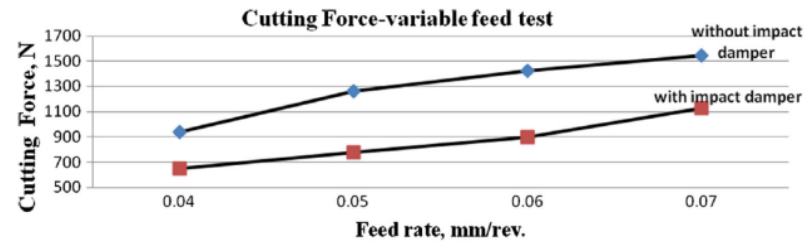

(a)

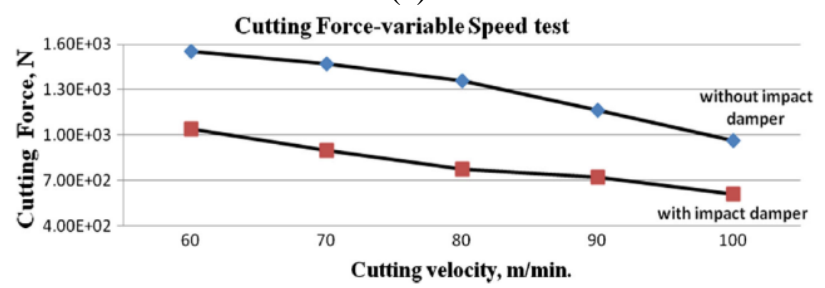

(b)

Şekil 8. a) kesme kuvveti - ilerleme grafiği

b) kesme kuvveti - kesme hızı grafiği [3]

Kesme kuvvetlerinin değerlendirildiği bir başka çalışmada, $0.8 \mathrm{~mm}$ uç yarıçapında CNMG geometrili kesici uçlar $\mathrm{Al}_{2} \mathrm{O}_{3}$ $+\mathrm{ZrO}_{2}$ ve $\mathrm{ZrO}_{2}$ kaplama malzemeleriyle (coating maerial) daldırma, döndürme ve püskürtme gibi çeşitli kaplama yöntemleriyle (coating mathod) kaplanarak çeşitli işleme koşullarında (lubricatioon system, yağlama koşulları kuru, gres yağı ve 1slak) delik içi tornalanarak kesme kuvvetleri ve yüzey pürüzlülüğü incelenmiştir. Çalışmada, daha iyi işleme performansı elde etmek için, kesici ucun, termal sprey kaplama tekniği ile çok katmanlı $\mathrm{TiO}_{2}+\mathrm{ZrO}_{2}$ olarak kaplanması gerektiği, ve soğutma sıvısının kullanılması gerektiği ifade edilmiştir. (Şekil 9) [27].

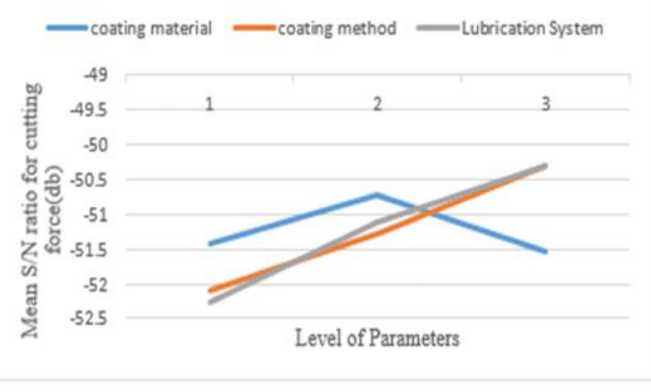

Şekil 9. Kesme kuvvetleri için S:N grafiğgi [27]

\section{Delik Barası Boy-Çap Oranı (L/D oranı) ve Taşma Oranı}

Delik içi tornalamada delik barası seçimi yapılırken işlenecek delik çapı ve uzunluğu dikkate alınmalıdır. Delik barası uzunluğunun (L) minimize edilmesi rijitlik, yüzey kalitesi ve ölçü hassasiyeti açısından önemlidir. Delik barası uzunluğunu delik derinliği belirlemektedir. Bara çapı arttıkça rijitlik artmaktadır ancak, talaş tahliyesi ve radyal hareketler açısından delik içerisindeki boşluğun da dikkate alınması gerektiğinden bara çapı açısından bazı sınırlamalar vardır. Rijitlik L/D oranı ile tanımlanmaktadır. L/D oranının artması rijitliği azaltacaktır (Şekil 10) ancak, işlenecek delik çap1 ve delik boyuna göre bu oranın belirlenmesi gerekmektedir. 


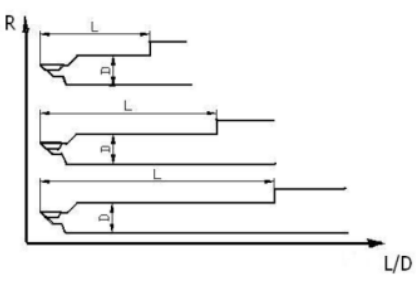

Şekil 10. L/D oranı ve rijitlik

Delik içi tornalamada L/D oranı için çeşitli çalışmalar yapılmıştır. Bara malzemelerinin ve L/D oranının işleme kararlılığına etkisinin araştırıldığı bir çalışmada, bara malzemesi, kesici uç yarıçapı ve iş parçası malzemesine bağlı olarak işleme kararlılığ 1 için kritik L/D oranına bağ $l_{1}$ model geliştirilmiştir. Kritik oran ( $\left(\mathrm{L}_{\mathrm{cr}}\right)$, işleme kararlılığını sağlayan maksimum en ve boy oranı olarak tanımlanmıștır. C45 ve ERGAL malzemeler üzerinde farklı kesici uç yarıçaplarının ( $\mathrm{re}=0.2-0.4-0.8-1.2-1.6$ ) çelik (standart alloy steel bars) ve karbür (high damping bars) baralar için ayrı ayrı kritik L/D oranı (L/D $\left.\mathrm{D}_{\mathrm{cr}}\right)$ ve bara çapı (bar diameter: D) incelenmiştir. Deneysel modele göre, bara çapı (D) sabit iken kesici uç yarıçap1 1.6 mm'den 0.2 mm’ye düştüğünde L/D kritik oranı (L/D) arttığ belirtilmiştir. (cutting pressure - malzeme kesme basıncı) Takım malzemesine göre ise kritik L/D oranının karbür takımda daha fazla arttığı ifade edilmiştir (Şekil 11) [28].
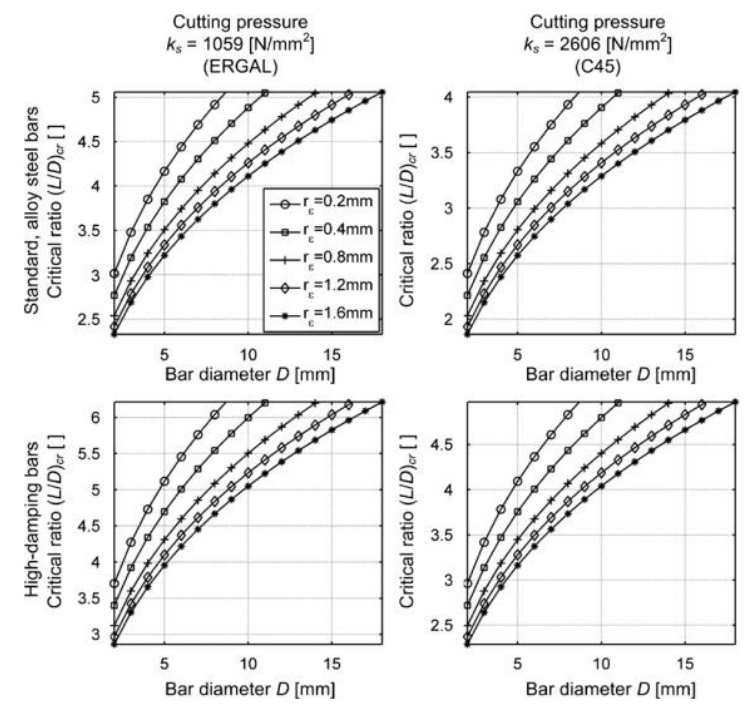

Şekil 11. ERGAL ve C45 malzemeler için delik barası malzemesine delik çapına ve kesici uç yarıçapına bağlı kritik L/D oranı [28]

Delik içi tornalamada kararlılık analizi için yeni bir olasılık algoritmasının sunulduğu bir çalışmada ise, delik işleme barası boyu (L) ile bara çapı (D) arasındaki maksimum oran tahmin edilmiştir. Önerilen yaklaşım, deneysel olarak doğrulanmıştır. Deneylerde 10 ve $16 \mathrm{~mm}$ çaplarında çelik ve karbür delik işleme baraları C45 ve A17075 malzemeler ve DCMT kodlu 0.2-0.4-0.6-0.8 mm yarıçaplarında kesici uçlar kullanılmıştır. Kararsızlık olasılığının \%10'dan küçük olduğunda sistemin kararlı olarak kabul edildiği vurgulanmıştır [29].

\section{Yüzey pürüzlülüğü}

Delik işleme çalışmalarında, işlenen yüzeyin pürüzlülüğüne etki eden faktörlerin belirlenmesine de çalışılmıştır. Örneğin, $16 \mathrm{~mm}$ çapında çelik delik işleme barası ve $0.2 \mathrm{~mm}$ ve 0.4 mm yarıçaplara sahip CCMT kodlu TiN kaplamalı karbür uçlar kullanılarak delik içi tornalamada, sönümleme pozisyonu, ilerleme, kesme derinliği ve kesici uç yarıçapı parametrelerinin yüzey pürüzlülüğü üzerindeki etkileri incelenmiştir. Yüzey pürüzlülüğü üzerinde en etkili parametrenin kesici uç yarıçapı olduğu belirtilmiştir. Kesici uç yarıçap1 arttığında yüzey pürüzlülüğü artmaktadır [30]. AISI 1030 düşük karbon çeliğinin delik içi tornalanmasında kesme sıvısının yüzey pürüzlülüğü üzerindeki etkisinin, kesme hızı, ilerleme hızı ve takım ucu yarıçapı gibi diğer kesme parametrelerine bağlı olarak incelendiği bir çalışmada, büyük uç yarıçapı ve düşük ilerleme oranı ile kullanılan kesme sıvısının, yüzey pürüzlülüğünü \% 80'e kadar iyileştirdiği belirtilmiştir. (Şekil 12) [8].

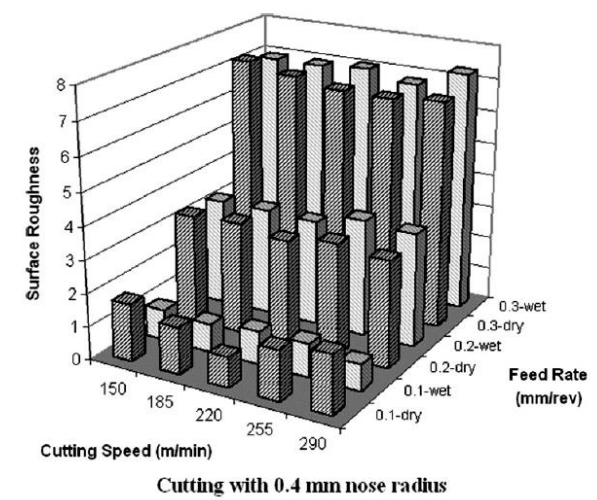

(a)

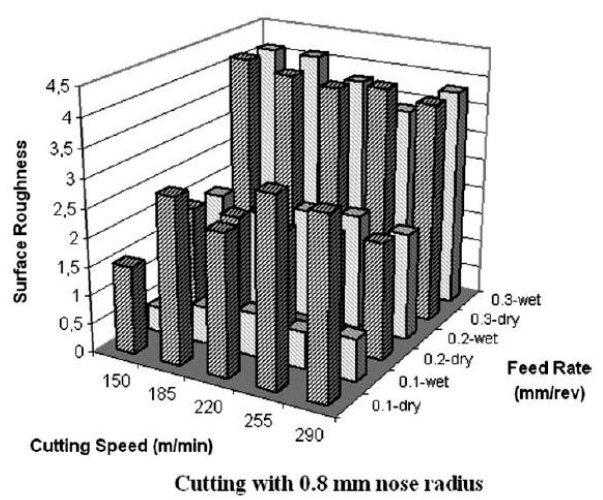

(b)

Şekil 12. Yüzey pürüzlülüğü grafikleri

a) Uç radüsü $0,4 \mathrm{~mm}$ b) Uç radüsü $0,8 \mathrm{~mm}$ [8]

İncelenen bir başka çalışmada, $10 \mathrm{~mm}$ çapında ve 65 ve 95 mm boylarda çelik ve karbür delik baraları, 0.4 ve $0.8 \mathrm{~mm}$ yarıçapında kesici uçlar kullanılarak AISI 1026 malzeme işlenmiştir. Kullanılan tüm deney parametrelerinde kısa bara uzunluğunun daha iyi yüzey pürüzlülüğü değerleri verdiği belirtilmiştir. Her iki delik işleme barası için de daha küçük yarıçapa sahip kesici uç ile daha iyi yüzey pürüzlülüğü değerinin elde edildiği ifade edilmiştir [31]. Dökme demir malzeme üzerinde kesme parametrelerinin yüzey pürüzlülüğüne etkisinin Taguchi metodu (L27) ile belirlendiği bir çalışmada ise, deney parametrelerin yüzey 
pürüzlülüğüne etkilerinin sırasıyla, kesme derinliği, ilerleme ve kesme hızı şeklinde olduğu belirtilmiştir [32].

\section{Sonuç}

$\mathrm{Bu}$ çalışmada, delik içi tornalamaya yönelik yapılmış çalışmalar ele alınmıştır. Ulaşılabilen tüm yayınlar tek tek incelenerek yapılan çalışmalar ve elde edilen sonuçlar bir araya toplanmaya çalışılmıştır. Yapılan değerlendirmeler sonucunda, elde edilen bulguların, delik barası ve kesici uç üzerinden tasnif edilmesinin daha uygun olacağı görülmüştür.

\section{Delik Barası}

Delik işleme operasyonlarında kullanılan delik barasının L/D oranın oldukça etkili olduğu ortaya çıkmıştır. Daha küçük L/D oranlarına sahip çelik malzemeli delik baralarının oldukça yaygın kullanıldığ 1 görülmüştür. Fakat artan L/D oranlarıyla çelik malzemeli delik işleme baralarının kararsız (titreşimin arttığı) hale geldiği görülmektedir. Karbür malzemeli delik işleme baralarının daha uzun L/D oranı ile sorunsuz olarak kullanılabildiği belirlenmiştir. Nanokompozit malzeme ile kaplanmış çelik baralarının, kaplamasız olanlarına göre delik işleme sırasında oluşan sesi yaklaşık \%90 oranında azalttığı belirtilmiştir. Vizkoelastik malzemelerle takviye edilmiş (PTFE) olan delik barasının yüzey pürüzlülüğünü yaklaşık $\% 25-30$ oranında azalttığ1 anlaşılmıştır. Parçacık sönümlü delik işleme baraları, standart bir çelik malzemeli delik barasının sorunlu olduğu L/D oranlarına sahip deliklerin işlenmesinde karbür baraların yerine basit ve ucuz bir alternatif olabileceğini göstermiştir. Parçacık sönümlemede parçacık boyutu ne kadar küçük olursa, sönümlemenin o kadar yüksek olduğu vurgulanmıştır. Yüksek yoğunluğa sahip malzemelerin ve sert parçacıkların daha iyi sönümleme sağladığ ve işlenen yüzeyin kalitesini iyileştirdiği anlaşılmıştır. Çelik bilyelerle yapılan sönümleme uygulamalarının, diğer sert parçacıklara kıyasla daha iyi yüzey kalitesi ortaya koyduğu ileri sürülmüştür. Karbon fiberli delik işleme baralarının delik işleme esnasında oluşturduğu titreşim frekansının normal bir delik barasına göre daha düşük oluştuğu açıklanmıştır. Teflon sönümleme malzemesi ile takviye edilmiş delik baralarının yüzey pürüzlülük değerini \%33'e kadar düşürebildiği ortaya konmuştur. Alüminyum malzemelerin, pasif sönümleme yöntemi ile takviye edilmiş delik baraları ile işlenmesinde titreşim seviyesini yaklaşık \% 61 azalttığını ve dolayısı ile de işlenen yüzey kalitesini \%88 arttırdığını yapılan çalışmalar göstermiştir. Delik işlemede meydana gelen konikliğin L/D oranının düşürülmesiyle büyük ölçüde ortadan kaldırılabildiği belirtilmiştir. Delik baralarında titreşim sönümleyiciler kullanıldığında delik barasının sönümleme kabiliyetinin ve kararlılığın arttığı anlaşılmıştır. Delik işleme baralarının sönümleme kabiliyeti ve sertliği arttığında takım aşınmasının azaldığ 1 görülmüştür. Sönümlemeli delik baraları ile yapılan delik işleme deneylerinde daha az ses ve daha uzun takım ömrü elde edildiği görülmüştür. Çelik delik barasının oluşturduğu titreşimin karbür delik barasına göre biraz daha yüksek oluğu anlaşılmıştır. Parçacık sönümleme tekniği ile üretilmiş delik baralarının gürültüyü önemli ölçüde azalttığı $\operatorname{artan}$ sönümlemenin de kesme kuvvetlerini etkili bir şekilde azalttığı ifade edilmiştir.

\section{Kesici uç}

Delik işleme operasyonlarında kullanılan kesici uç yarıçapının yüzey pürüzlülügü üzerinde yüksek etkiye sahip oluğunu yapılan deneysel çalışmalar göstermiştir. Daha küçük kesici uç yarıçap1 ve yüksek pozitif eğim açısı, minimum yüzey pürüzlülüğü vermiştir. Düşük ilerleme hızlarında büyük kesici uç yarıçapı, ıslak işlemede yüzey pürüzlülüğünde \%80'e varan iyileşmeler sağlanmıştır. Sert malzemelerin işlenmesinde $\mathrm{CBN}$ kesici uçlarla daha iyi sonuçlar elde edilmiştir. Kesici uç yarıçapı iş parçasının titreşim genliğini etkileyen önemli parametredir. Baskın aşınma tipleri serbest yüzey aşınması ve krater aşınmasıdır. Kaplamasız karbür kesici uçlarda serbest yüzey aşınması meydana gelmiştir. CBN uçlarda serbest yüzey ve krater aşınması etkindir. Aşınma mekanizmaları aşındırıcı ve difüzyondur. Sprey kaplama tekniği ile çok katmanlı $\left(\mathrm{TiO}_{2}\right.$ $\left.+\mathrm{ZrO}_{2}\right)$ kaplanan kesici uçlar ıslak işleme ortamında daha yüksek kesme performansına sahiptir. Delik barası çapı sabit iken kesici uç yarıçapı azaldığında sorunsuz olarak kullanılabilen L/D oranının da arttığı görülmüştür. Kesici uç yarıçapı arttığında artan titreşim ile yüzey pürüzlülüğünün de arttığ 1 belirtilmiştir.

\section{Teşekkür}

Katkılarından dolayı Gazi Üniversitesi Bilimsel Araştırma Projeleri (BAP) Birimine teşekkür ederiz.

\section{Kaynaklar}

[1] Badadhe, A. M., Bhave, S. Y., and Navale, L. G. "Optimization of cutting parameters in boring operation" In Second National Conference on Recent Developments in Mechanical Engineering, pp. 10-15, 2005.

[2] Patil, R. S., Jadhav, S. M., and Gajjal, S. Y., "Improvement of Surface roughness in Boring operation using Viscoelastic Material Damper”, 2016.

[3] Lawrance, G., Paul, P. S., Varadarajan, A. S., Praveen, A. P., and Vasanth, X. A., "Attenuation of vibration in boring tool using spring controlled impact damper", International Journal on Interactive Design and Manufacturing (IJIDeM), 11(4), 903-915., 2017 DOI:10.1007/s12008-0150292-1.

[4] Wadhwankar, D., More, K., and Bajaj, V. "Experimental Investigation of Boring Tool Vibration for Improving Surface Finish by using Passive Damper", International Journal of Current Engineering and Technology, 6,162., 2016 DOI:10.1007/s00170-016-8964-y

[5] Suyama, D. I., Diniz, A. E., and Pederiva, R. "Tool vibration in internal turning of hardened steel using cBN tool", The International Journal of Advanced Manufacturing Technology, 88(9-12), 2485-2495, 2017.

[6] Korkut, I., and Kucuk, Y. "Experimental analysis of the deviation from circularity of bored hole based on the Taguchi method", Strojniški vestnik-Journal of Mechanical Engineering, 56(5), 340-346. 2010 
[7] Munawar, M., Chen, J. C. S., and Mufti, N. A. "Investigation of cutting parameters effect for minimization of sur face roughness in internal turning", International journal of precision engineering and manufacturing, 12(1), pages 121-127,DOI: 10.1007/s12541-011-0015-x, 2011.

[8] Yildiz, Y., Gunay, M., and Seker, U. "The effect of the cutting fluid on surface roughness in boring of low carbon steel-technical communication", Machining Science and Technology, 11(4), pages 553-560 DOI:10.1080/10910340701697052, 2007.

[9] Boy, M., Ciftci, I., Gunay, M., Ozhan, F., “Application of the Taguchi method to optimize the cutting conditions in hard turning of a ring bore", Materials in Technology, 49 (5) pages 765-772, (2015). DOI:10.17222/mit. 2014.246

[10] Kahraman, F., Başar, G., Koçoğlu, Z., ve Yeniyıl, E.’Delik Büyütme İşleminde Kesme Parametrelerinin Çok Yanıtlı Taguchi Deneysel Tasarım Yaklaşımı Kullanılarak Optimizasyonu" Politeknik Dergisi. 2017.

[11] Rao, K. V., Murthy, B. S. N., and Rao, N. M. "Cutting tool condition monitoring by analyzing surface roughness, work piece vibration and volume of metal removed for AISI 1040 steel in boring", Measurement, 46(10), pp 40754084,2013.

http://dx.doi.org/10.1016/j.measurement.2013.07.021

[12] Ramesh, K., Baranitharan, P., and Sakthivel, R. "Investigation of the stability on boring tool attached with double impact dampers using Taguchi based Grey analysis and cutting tool temperature investigation through FLUKEThermal imager", Measurement, 131, pp 143-155, 2019. https://doi.org/10.1016/j.measurement.2018.08.055

[13] Rao, K. V., Murthy, B. S. N., and Rao, N. M. "Prediction of cutting tool wear, surface roughness and vibration of work piece in boring of AISI 316 steel with artificial neural network", Measurement, 51, pp 63-70, 2014.http://dx.doi.org/10.1016/j.measurement.2014.01.024

[14] Yuvaraju, B. A. G., \& Nanda, B. K. "Prediction of vibration amplitude and surface roughness in boring operation by response surface methodology", Materials Today: Proceedings, 5(2), pp 6906-6915, 2018.

[15] Fu, Q., Lundin, D., \& Nicolescu, C. M. “Anti-vibration engineering in internal turning using a carbon nanocomposite damping coating produced by PECVD process", Journal of materials engineering and performance, 23(2), pp 506-517, 2014. DOI:10.1007/s11665-013-0781-y.

[16] Patil, R. S., and Jadhav, S. M. "Boring parameters optimization for minimum surface roughness using CNC boring machine with passive damping material" In Convergence in Technology (I2CT), 2nd International Conference for, pp. 300-303 April 2017, IEEE.

[17] Suyama, D. I., Diniz, A. E., and Pederiva, R. "The use of carbide and particle-damped bars to increase tool overhang in the internal turning of hardened steel", The
International Journal of Advanced Manufacturing Technology, 86(5-8), pp 2083-2092, 2016. DOI:10.1007/s00170-015-8328-z

[18] Sathishkumar, B., Mohanasundaram, K. M., and Kumar, M. S. "Impact of Particle Damping Parameters on Surface Roughness of Bored Surface" Arabian Journal for Science and Engineering,39(10), pp 7327-7334, 2014. DOI:10.1007/s13369-014-1209-1.

[19] Rayate, A. V., Patil, S. J., Pawar, S. S., Mundhe, N. P., and Jadhav, S. M. "Vibration Reduction and Surface Finish Improvement in Boring Operation on Lathe by Viscoelastic Material Damper", 2017.

[20] de Aguiar, H. C. G., Hassui, A., Suyama, D. I., \& Magri, A."Reduction of internal turning surface roughness by using particle damping aided by airflow", The International Journal of Advanced Manufacturing Technology, 106(1-2), pp 125-131 2020 https://doi.org/10.1007/s00170-019$\underline{04566-5}$

[21] Sarode, M. K., Nehe, P., and Deshpande, M. S. "Chatter mitigation in boring machining process" International journal, 5(9), 2020.

[22] Kucuk, Y., and Korkut, I. "Using the Experimental Design Method to Optimize the Conicity and Circularity of Bored Holes", Arabian Journal for Science and Engineering, 37(4), pp 1077-1082, 2012. DOI:10.1007/s13369-012-0215-4

[23] Baranitharan, P. "Investigation on the effects of damping over the temperature distribution on internal turning bar using Infrared fusion thermal imager analysis via Smart View software" Measurement, 107938, 2020. https://doi.org/10.1016/j.measurement.2020.107938

[24] Suyama, D. I., and Diniz, A. E. "Influence of tool vibrations on tool wear mechanisms in internal turning of hardened steel" Journal of the Brazilian Society of Mechanical Sciences and Engineering, 42(7), pp 1-17, 2020. https://doi.org/10.1007/s40430-020-02452-w

[25] Singh, G., Mann, G. S., and Pradhan, S. "Improving the Surface roughness and Flank wear of the boring process using particle damped boring bars" Materials Today: Proceedings, 5(14), pp 28186-28194, 2018.

[26] Rocha, C. A., Sales, W. F., de Barcellos, C. S., and Abrão, A. M, "Evaluation of the wear mechanisms and surface parameters when machining internal combustion engine valve seats using PCBN tools" Journal of materials processing technology, 145(3), pp 397-406, 2004.

[27] Lawrance, G., Daniel, E., Paul, P. S., Shaji, J., and Thankachan, T. "Study on the Influence of Multi-Layered Nano Metal Oxide Coating on Cutting Performance During Boring of Hardened Steel", Materials Today: Proceedings, 22, pp 1731-1736, 2020.

[28] Sortino, M., Totis, G., and Prosperi, F. "Development of a practical model for selection of stable tooling system 
configurations in internal turning" International Journal of Machine Tools and Manufacture, 61, pp 58-70., 2012. http://dx.doi.org/10.1016/j.ijmachtools.2012.05.010

[29] Totis, G., and Sortino, M. "Robust analysis of stability in internal turning" Procedia Engineering, 69, pp 13061315, 2014. DOI :10.1016/j.proeng.2014.03.123

[30] Nugroho, W., Baba, N. B., and Saptari, A “Optımızatıon on Surface Roughness of Borıng Process By Varyıng Damper Position" 2006.

[31] Beauchamp, Y., Thomas, M., Youssef, Y. A., \& Masounave, J. "Investigation of cutting parameter effects on surface roughness in lathe boring operation by use of a full factorial design" Computers \& industrial engineering, 31(34), pp 645-651, 1996.

[32] Rai, A. K., Yadav, S., Dubey, R., and Sachan, V. "Application of Taguchi Method in the Optimization of Boring Parameters" International Journal of Advanced Research in Engineering \& Technology (IJARET), 4(4), pp 191-199, 2013. 